\title{
High Temperature Oxidation and Hot Corrosion Behaviour of Yttria- Stabilised Zirconia as Plasma Sprayed Coating in Air and Salt at $900^{\circ} \mathrm{C}$ under Cyclic Condition
}

\author{
Dinesh Gond $^{\mathrm{a}^{*}}$, R.S. Lalbondre ${ }^{\mathrm{b},}$ D. Puri ${ }^{\mathrm{c}}$, S. Prakash ${ }^{\mathrm{c}}$
}

${ }^{a}$ HEEP, Bharat Heavy Electricals Ltd. (Government of India Undertaking) Haridwar, India.

${ }^{\mathrm{b}}$ Mechanical Engineering Department, National Institute of Technology, Suratkal, India

${ }^{c}$ Metallurgical \& Materials Engineering Department, Indian Institute of Technology Roorkee, India

\begin{abstract}
*Corresponding author: dinesh_gond@yahoo.co.in, dlgond@gmail.com.
\end{abstract}
\begin{abstract}
Yttria-Stabilised Zirconia (YSZ) coatings were deposited on a T-91 boiler steel. NiCrAlY was used as bond coat and YSZ as top coat. Hot corrosion studies were conducted on uncoated as well as plasma spray coated specimens in air as well as salt (75wt. $\% \mathrm{Na}_{2} \mathrm{SO}_{4}+25 \mathrm{wt}$. \% $\mathrm{NaCl}$ ) at $900^{\circ} \mathrm{C}$ under cyclic conditions. The thermogravimetric technique was used to establish kinetics of corrosion. X-ray diffraction (XRD) and scanning electron microscopy/energy-dispersive $x$-ray analysis (SEM/EDAX) techniques were used to analyse the corrosion products. This YSZ overlay coatings enhance resistance to corrosion significantly which can be attributed to formation of zirconium oxides $\left(\mathrm{ZrO}_{2}\right)$ and yttrium oxide $\left(\mathrm{Y}_{2} \mathrm{O}_{3}\right)$. This coating was more effective in salt environment and there is an extra phase of $\mathrm{ZrS}$.
\end{abstract}

Keywords: Hot corrosion; T-91; Plasma spray coating. 


\section{INTRODUCTION}

In a wide variety of applications, mechanical components have to operate under severe conditions, such as high load, speed or temperature and hostile chemical environment. Thus, their surface modification is necessary in order to protect them against various types of degradation. Ceramic coatings produced by thermal spray techniques are widely used for a range of industrial applications, to confer wear and erosion resistance, corrosion protection and thermal insulation [1-4].

Thermal barrier coating (TBC) systems are used in thermal insulating components in the hot sections of gas turbines in order to increase operational temperature with better efficiency [511]. Yttria stabilized zirconia (YSZ) has been usually chosen for the top insulating coat material because of its high thermal expansion coefficient, which closely matches that of the substrate. [6,7]. Apart from this application TBC is also useful in aerospace, aircraft and boiler applications.

The different functions of the coating, such as wear and corrosion resistance, thermal or electrical insulation can be achieved using different coating techniques and coating materials. The purpose of a hot corrosion resistant coating is to serve as an effective solid-state diffusion barrier between oxygen (or other gases) and base metal [12].

Mostly metals and alloys experience accelerated oxidation when their surfaces are covered with a thin film of fused salt in an oxidising gas atmosphere at elevated temperatures. This is known as hot corrosion where a porous non-protective oxide scale is formed at the surfaces and sulphides in the substrate [13].

The research work deals with development of NiCrAlY as bond coat and YSZ as top coat on T-91 boiler steels and their characterisation. X-ray diffraction (XRD) and scanning electron microscopy/energy-dispersive analysis (SEM/EDAX) techniques have been used to characterise coating and respective corrosion products after hot corrosion at $900{ }^{\circ} \mathrm{C}$.

\section{EXPERIMENTAL PROCEDURE}




\subsection{Development of Coatings}

\subsubsection{Substrate material}

The experimental work was performed by using samples of T-91 boiler steel. The T-91 steel samples were obtained from Gurunank Dev Power plant, Bhatinda, Punjab, India. The spectroscopic analysis of candidate material is given below in Table 1.

Table 1: Spectroscopic analysis of T-91 boiler steel.

\begin{tabular}{lccccccc}
\hline Type of steel & $\mathrm{C}$ & $\mathrm{Mn}$ & $\mathrm{Si}$ & $\mathrm{Cr}$ & $\mathrm{Mo}$ & $\mathrm{Cu}$ & $\mathrm{Fe}$ \\
\hline $\mathrm{T}-91$ & 0.0607 & 0.3874 & 0.2297 & 8.078 & 0.8029 & 0.1168 & Balance \\
\hline
\end{tabular}

The specimens each measuring approximately 20 x $15 \times 3.5 \mathrm{~mm}$ was obtained from T-91 boiler pipe. The specimens were polished and grit blasted with alumina powders (grit 60) before being plasma sprayed.

\subsubsection{Coating powders}

Yttria stabilised zirconia (YSZ; $\mathrm{ZrO}_{2}-8 w t . \% \mathrm{Y}_{2} \mathrm{O}_{3}$ ) and NiCrAlY (Ni-22Cr-10Al-1Y) is been used for TBC coating which were applied on samples by plasma spray process. The chemical composition and particle size for these powders are given in Table 2.

Table 2: Composition, mean particle size and manufacturing of coating powders.

\begin{tabular}{lccc}
\hline $\begin{array}{l}\text { Coating } \\
\text { powder }\end{array}$ & Composition (wt. \%) & $\begin{array}{c}\text { Mean particle } \\
\text { size }(\mu \mathrm{m})\end{array}$ & Manufacturer \\
\hline NiCrAlY & $\mathrm{Cr}(21-23), \mathrm{Al}(7-9), \mathrm{Y}(0.8-1.2), \mathrm{Ni}$ & & \\
YSZ & (Balance) & $38-106$ & METCO, Corp. USA \\
\hline
\end{tabular}

\subsubsection{Coating formulation}

Samples were grit blasted before plasma spraying. $40 \mathrm{~kW}$ Miller thermal plasma spray apparatus available with Anod Plasma Spray Ltd., Kanpur (India) has been used to apply the 
coatings. Argon was used as powder carrying and shielding gas. All the process parameters including the spray distance were kept constant throughout coating process. $\mathrm{Ni}-22 \mathrm{Cr}-10 \mathrm{Al}-$ $1 Y$ powder was sprayed as a bond coat of around $150 \mu \mathrm{m}$ thickness before applying the final coatings of YSZ around $200 \mu \mathrm{m}$ and the process parameters were as reported in Table 3.

Table 3: Parameters of argon shrouded plasma spray process used for coating.

\begin{tabular}{lc}
\hline Arc current (A) & 750 \\
Arc voltage (V) & 50 \\
Powder flow rate (rev/min) & 3.2 \\
Spraying distance (mm) & $90-110$ \\
Plasma arc gas (argon) (psi) & 59 \\
Carrier gas (psi) & 40 \\
\hline
\end{tabular}

\subsubsection{Porosity measurement}

Coated samples were subjected to porosity measurements with the help of Image Analyser having software of Dewinter Material Plus 1.01 based on ASTM B487. The images were obtained through the attached PMP3 Inverted Metallurgical Microscope made in Japan. The porosity values were then determined.

\subsection{High Temperature Oxidation Study in Air and Salt}

Hot corrosion studies were conducted at $900^{\circ} \mathrm{C}$ in laboratory using silicon carbide tube furnace having PID temperature controller (make Digitech, India). The bare samples were subjected to mirror polishing including cloth polish. Dimensions were accurately measured by digital vernier (make Mototoyo, Japan) to calculate area of sample. Finally specimens were cleaned i.e. degreased by ethanol and kept in alumina boat. Prior to experiment alumina boat was kept in oven for $5 \mathrm{hr}$ at $250^{\circ} \mathrm{C}$ in oven and then kept in furnace at $900^{\circ} \mathrm{C}$ for $2 \mathrm{hr}$ to expel all the moisture. After this samples of T-91 bare steel were kept in alumina boat and then inserted in the tubular furnace for $1 \mathrm{hr}$ at a temperature of $900^{\circ} \mathrm{C}$ and then they were removed and cooled further for 20 minutes to room temperature and their weights were measured. In case of hot corrosion in the given salt environment of $75 \mathrm{wt}$. $\% \mathrm{Na}_{2} \mathrm{SO}_{4}+25 \mathrm{wt}$. $\% \mathrm{NaCl}$ for as sprayed samples each cycle consisted of $1 \mathrm{hr}$ heating at $900^{\circ} \mathrm{C}$ followed by 20 min. cooling at room temperature. 
The salt coating of uniform thickness with $3-5 \mathrm{mg} / \mathrm{cm}^{2}$ of $75 \mathrm{wt}$. $\% \mathrm{Na}_{2} \mathrm{SO}_{4}+25 \mathrm{wt}$. \% $\mathrm{NaCl}$ was applied with camel hairbrush on the preheated samples $\left(250^{\circ} \mathrm{C}\right)$. After the salt application the samples were kept in an oven for $2 \frac{1 / 2}{\mathrm{hr}}$ at $250^{\circ} \mathrm{C}$ and then cyclic oxidation test was carried out on samples. The samples were subjected to weight change measurements after visual observation at the end of each cycle. Weight was taken with help of Electronic Balance Model CB-120 (Contech, Mumbai, India) with a sensitivity of 0.001 gms. Burnt oxide layer which were spalled out in boat were also taken into consideration i.e. the weight was taken along with the boat. This cycle was repeated for 50 times i.e. 50 cycles were made for each sample. Corroded samples from air and salt environment were analysed by XRD (BRUKER-binary V3) and SEM/EDAX and the oxide scale which fell into the boat were also analysed by XRD. Cu radiation was used in XRD at a step of $2 \%$ min and the range of angle was $5-100^{\circ}$.

\section{EXPERIMENTAL RESULTS}

\subsection{Behaviour in Air and Salt at Elevated Temperature}

The weight gain plots for the substrate without coating and with coatings have been shown in Fig. 1 in the presence of air and salt layer of $75 \mathrm{wt}$. $\% \mathrm{Na}_{2} \mathrm{SO}_{4}+25 \% \mathrm{wt} \mathrm{NaCl}$ at $900^{\circ} \mathrm{C}$. On $\mathrm{x}-$ axis "number of cycles” and on y-axis “weight gain/area $\left(\mathrm{mg} / \mathrm{cm}^{2}\right)$ " was taken. In case of air oxidation, hot corrosion behaviour of T-91 bare steel in air was somewhat linear because the oxide layer formed on substrate used to peel of very easily and as compared to this oxidation rate of T-91 YSZ coated sample was too less i.e. nearly 53.79\% less as compared to bare steel. In case of salt oxidation, T-91 bare steel behaviour was parabolic but T-91 YSZ coated sample showed more resistance to oxidation than the bare sample i.e. nearly $73.58 \%$ less as compared to bare steel. The graph reveals that T-91 YSZ coated steel is better than T-91 bare steel in an environment of air and salt for 50 cycles. Fig. 2 shows plot of (weight gain/area) ${ }^{2}$ vs. Number of cycles. In this plot every curve is associated with straight line of same colour. This straight line is trend line and it is used to calculate rate constant $\left(\mathrm{K}_{\mathrm{p}}\right)$ which is given in Table 4.

Every line or curve in graph is having its approximate equation which is given below.

For T-91 air oxidised bare sample the approximated curve equation is 


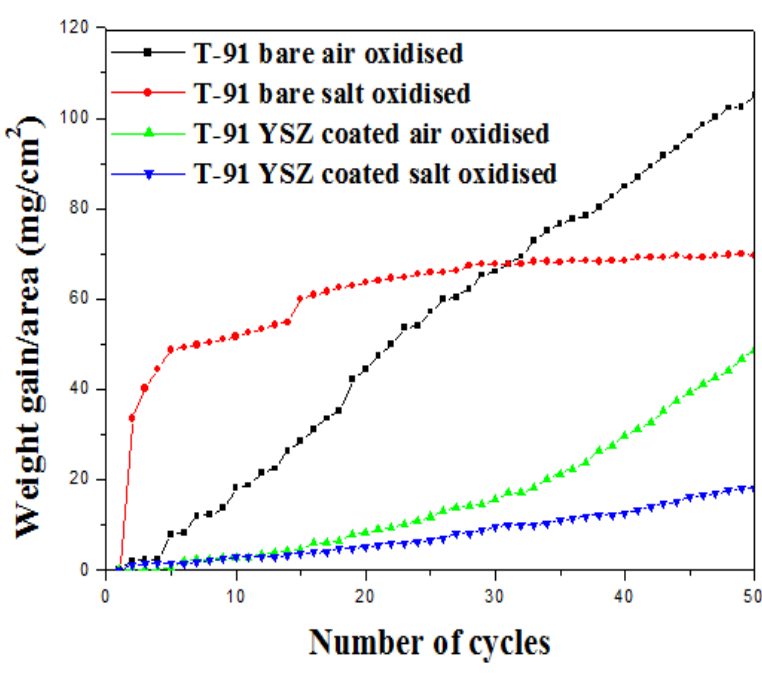

Fig 1. Weight gain vs. number of cycles plot for coated and uncoated T-91 steel subjected to cyclic oxidation for 50 cycles in air and salt at $900^{\circ} \mathrm{C}$.

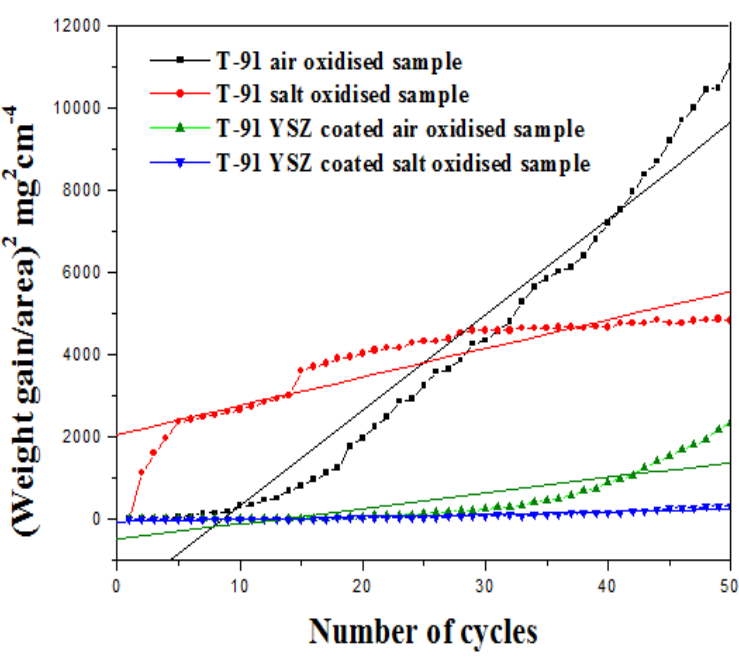

Fig 2. (Weight gain/area) ${ }^{2}$ vs. number of cycles plot for coated and uncoated T-91 steel subjected to cyclic oxidation for 50 cycles in air and salt at $900^{\circ} \mathrm{C}$

For T-91 air oxidised YSZ coated sample the approximated curve equation is $\mathrm{Y}=1.56652-0.13746 * \mathrm{X}-0.0212 * \mathrm{X}^{\wedge} 2$

For T-91 salt oxidised bare sample the approximated curve equation is $\mathrm{Y}=30.52124-2.19772 * \mathrm{X}-0.03 * \mathrm{X}^{\wedge} 2$

For T-91 salt oxidised YSZ coated sample the approximated curve equation is $\mathrm{Y}=0.56075-0.15298 * \mathrm{X}-0.00408 * \mathrm{X}^{\wedge} 2$

(Where $\mathrm{X}$ is number of cycle and $\mathrm{Y}$ is weight gain/area \& these equation are calculated by using analysis mode of Origin software)

Table 4: Value of the rate constant $\mathrm{K}_{\mathrm{p}}$

\begin{tabular}{lc}
\hline Description & $\mathrm{K}_{\mathrm{p}}\left(10^{-6} \mathrm{~g}^{2} \mathrm{~cm}^{-4} \mathrm{~s}^{-1}\right)$ \\
\hline T-91 bare air oxidised & 64 \\
T-91 bare salt oxidised & 19 \\
T-91 YSZ coated air oxidised & 10 \\
T-91 YSZ coated salt oxidised & 1.7 \\
\hline
\end{tabular}

As shown in macrograph Fig. 3(a) extrusion of material from beneath and cracks in the scale were observed during hot corrosion runs for T-91 bare air oxidised sample but T-91 bare salt oxidised sample did not showed much more crack or extrusion of material from beneath as is 
evident from Fig. 3(b). Some cracks were observed in T-91 YSZ coated air oxidised sample Fig. 3(c) and due to this, corrosion occurred beneath the coating while in case of T-91 YSZ coated salt oxidised sample Fig. 3(d) cracks did not occurred in coating so there was no corrosion which is revealed in Fig. 7 (c and d).

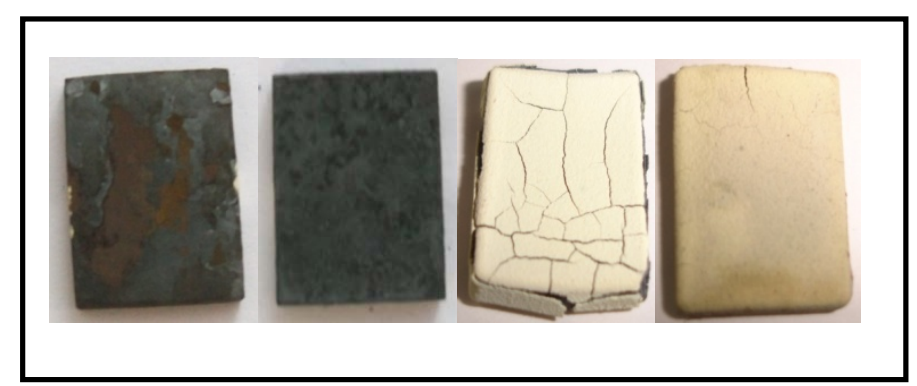

$\begin{array}{llll}\text { (a) } & \text { (b) } & \text { (c) } & \text { (d) }\end{array}$

Fig.3.Macrograph of (a) T-91 bare air oxidised (b) T-91 bare salt oxidised (c) T-91 YSZ coated air oxidised (d) T-91 YSZ coated salt oxidised.

\subsection{X-Ray Diffraction Analysis}

The samples and their scales after oxidation were removed from boat and they were analysed separately by XRD and after that only oxidised sample were analysed by SEM /EDAX. The results of XRD analysis contained graph indicating peak values (i.e. d values) which were used to identify various phases with the help of inorganic X-ray Diffraction data card from Powder diffraction file of JCPDS. Help of Philips X' pert High score software was also taken for finding out compounds at respective peaks.

\subsubsection{XRD result for T-91 bare and YSZ coated air and salt oxidised sample}

From the X-Ray Diffraction analysis it is found that ferrous oxide $\left(\mathrm{Fe}_{2} \mathrm{O}_{3}\right)$, chromium ferrous oxide (Cr, Fe) $)_{2} \mathrm{O}_{3}$ are mainly formed along with $\mathrm{Cr}_{2} \mathrm{O}_{3}$ in T-91 bare air oxidised sample Fig. 4 ( $\mathrm{p}$ and $\mathrm{q}$ ) and T-91 bare salt oxidised sample Fig. 5 ( $\mathrm{x}$ and y) $\mathrm{Fe}_{2} \mathrm{O}_{3}, \mathrm{Cr}_{2} \mathrm{O}_{3}$ form a protective oxide layer at surface due to which further oxidation is prevented as it acts as barrier for further corroding media to interact with substrate but at initial stage as the substrate material was in direct contact of corroding media so there was accelerated corrosion at initial stage. 


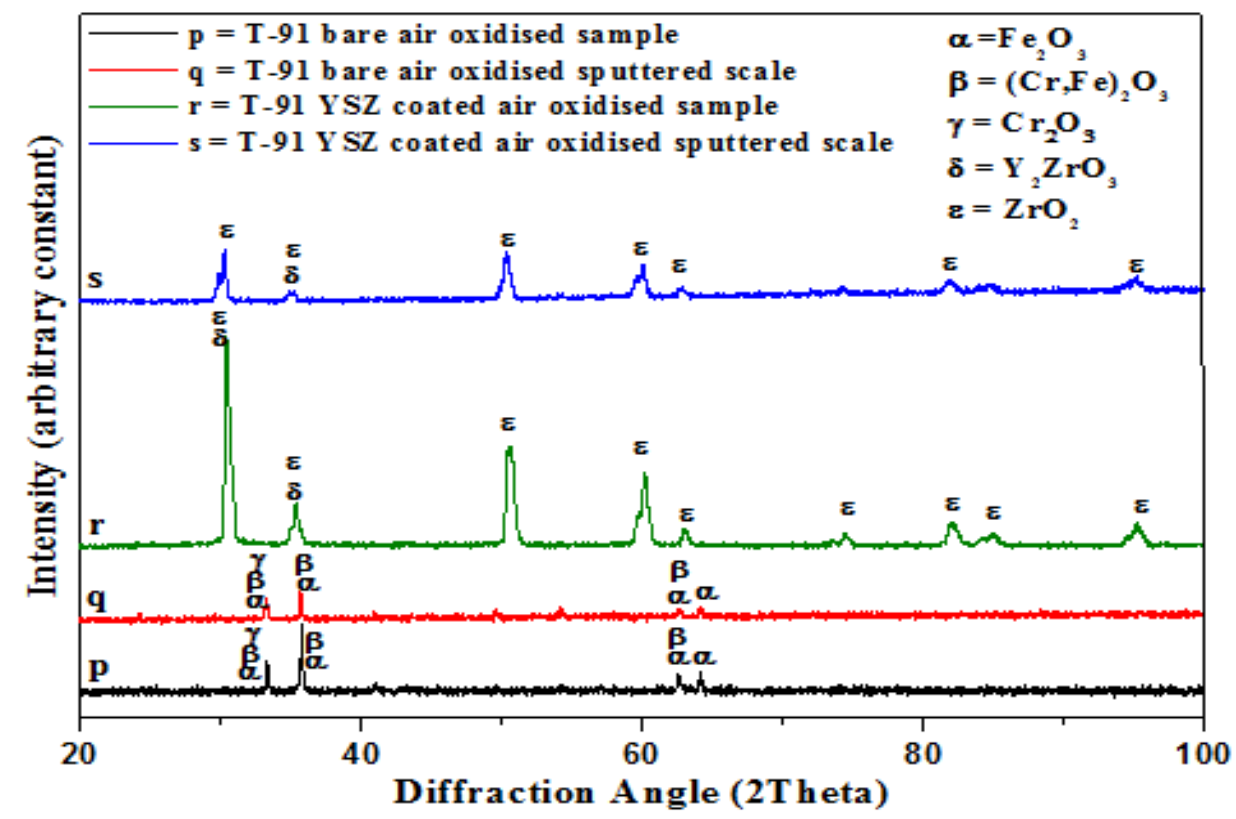

Fig 4. XRD patterns for T-91 steel subjected to cyclic oxidation in air at $900^{\circ} \mathrm{C}$ after 50 cycles. (p) T-91 bare sample (q) T-91 bare sputtered scales (r) T-91 YSZ coated sample (s) T-91 YSZ coated sputtered scales.

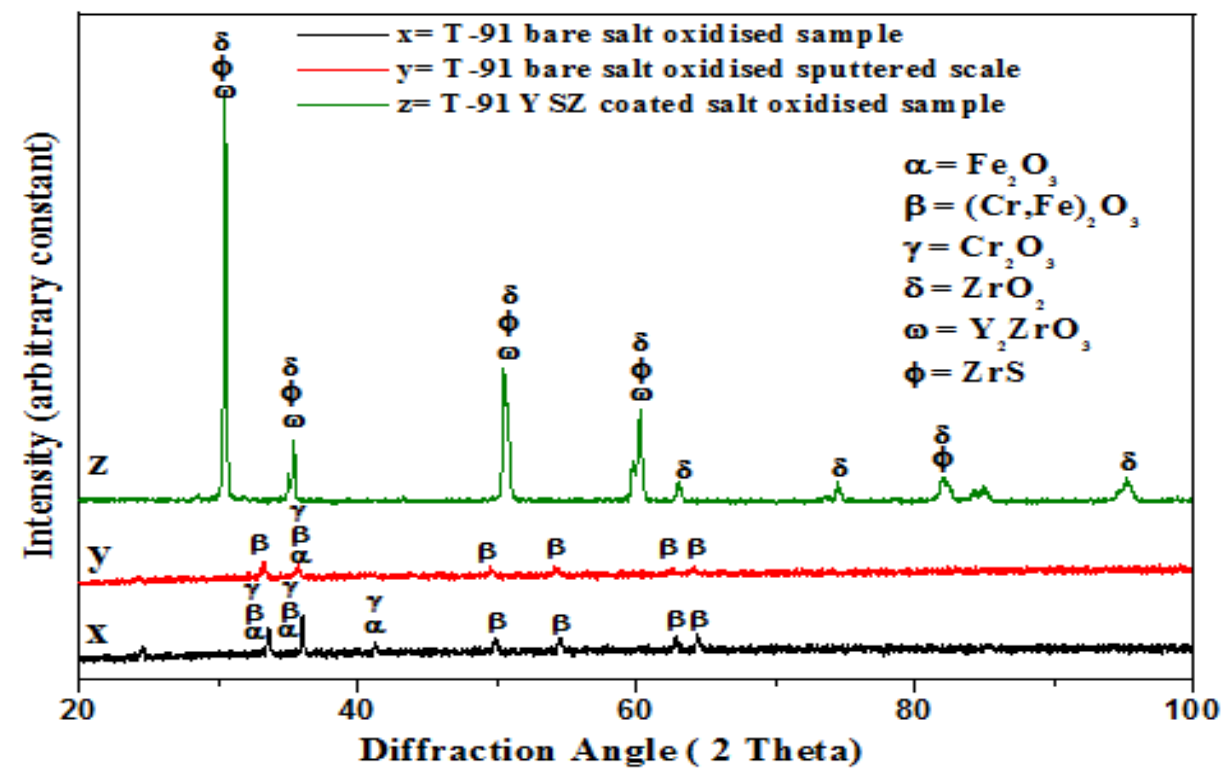

Fig 5. XRD patterns for T-91 steel subjected to cyclic oxidation in $\mathrm{Na}_{2} \mathrm{SO}_{4}+25$ wt.\% $\mathrm{NaCl}$ salt at $900^{\circ} \mathrm{C}$ after 50 cycles. (x) T-91 bare sample (y) T-91 bare sputtered scales (z) T-91 YSZ coated sample. 
In case of coated samples the case of accelerated corrosion was absent due to the overlay coating of Yttria stabilised zirconia (YSZ). In T-91 YSZ coated air oxidised sample Fig. 4(r and s) and T-91 YSZ coated salt oxidised sample Fig. 5(z) there is formation of mainly $\mathrm{ZrO}_{2}$, $\mathrm{Y}_{2} \mathrm{ZrO}_{3}$ and in case of YSZ coated salt oxidised sample apart from this $\mathrm{ZrS}$ was also formed.

\subsection{Energy Dispersive X-Ray (EDAX) Studies}

\subsubsection{Surface scale}

The SEM/EDAX analysis for T-91 bare sample after oxidation in air for 50 cycles at $900^{\circ} \mathrm{C}$ is shown in Fig. 6 (a). The oxide scale reveals the dominance of $\mathrm{Fe}_{2} \mathrm{O}_{3}$ and along with this compounds of $\mathrm{Mo}_{2} \mathrm{O}_{3}$ and $\mathrm{Cr}_{2} \mathrm{O}_{3}$ are also formed. The obtained morphology indicates that the oxide formed is layer-wise i.e. one below the other and the weight wise composition is approximately same but it greatly differs in case of Cr content. The upper layer contains nearly no Cr but the lower layer is rich in Cr content. T-91 bare salt oxidised sample Fig 6(b) reveals that the oxide formed is layer wise and it contains granules. Analysis of these granules revealed that they were formed when the amount of chromium oxide was less in it i.e. at about $1-2 \%$.and it showed some cracking in oxide layer.
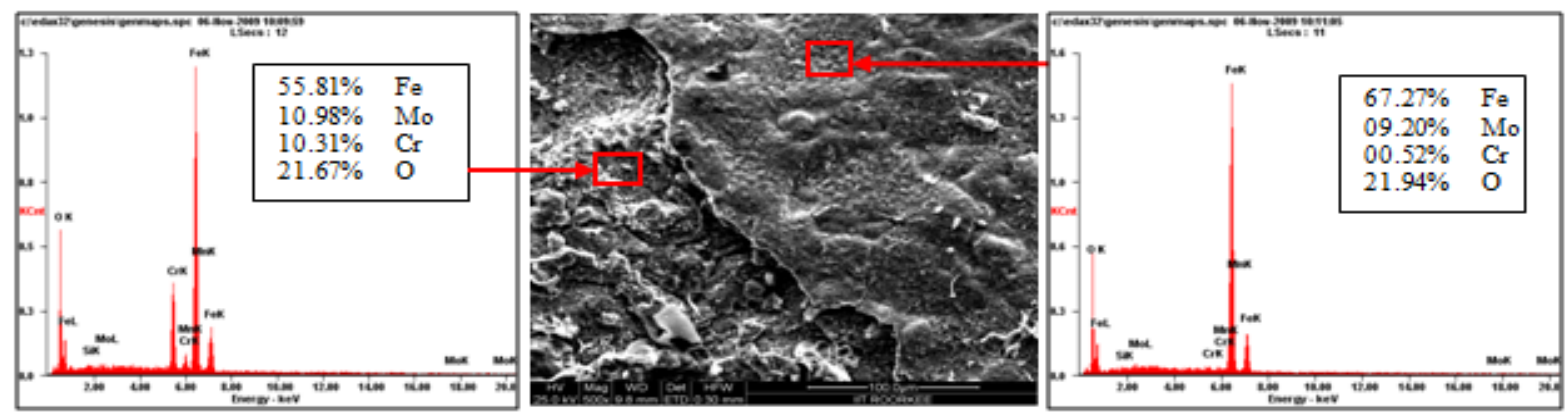

(a) T-91 bare air oxidised sample at scale of $100 \mu \mathrm{m}$

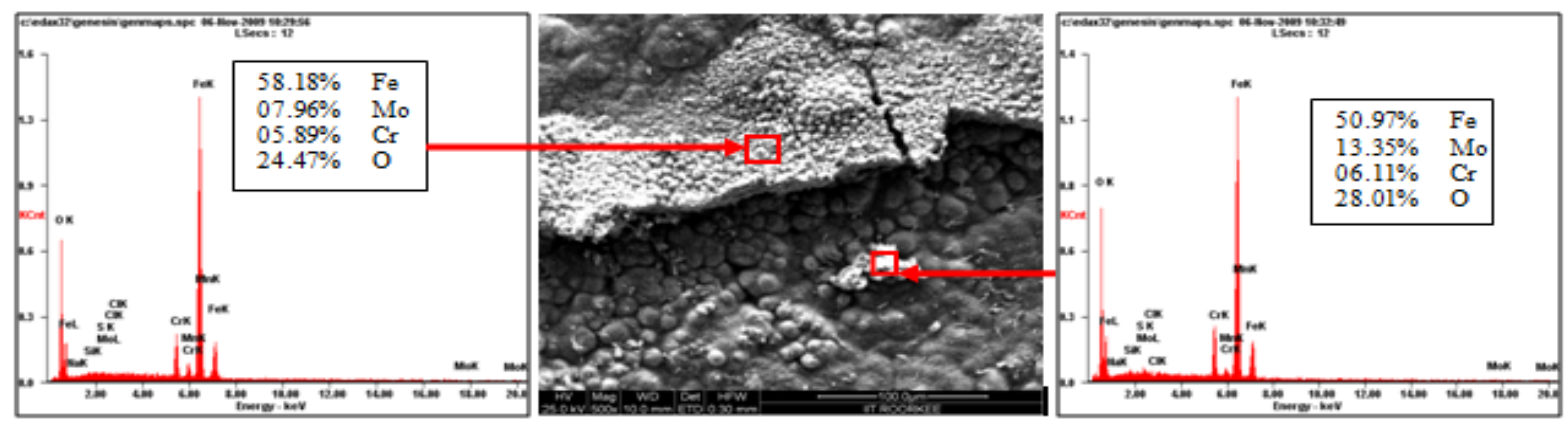


(b) T-91 bare salt oxidised sample at scale of $100 \mu \mathrm{m}$
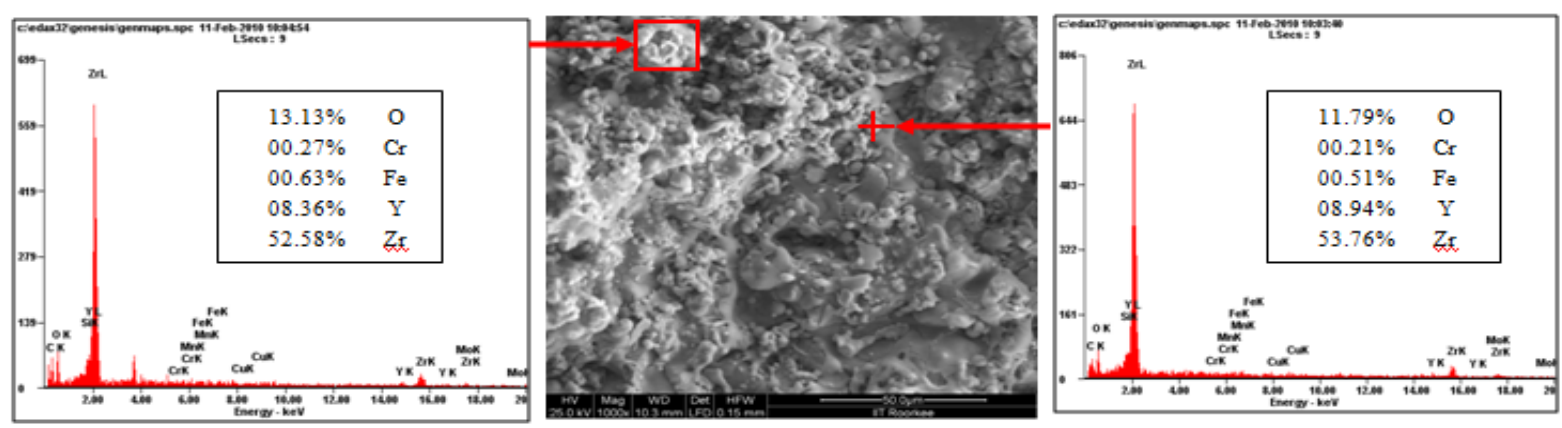

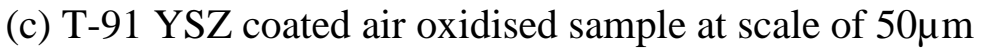
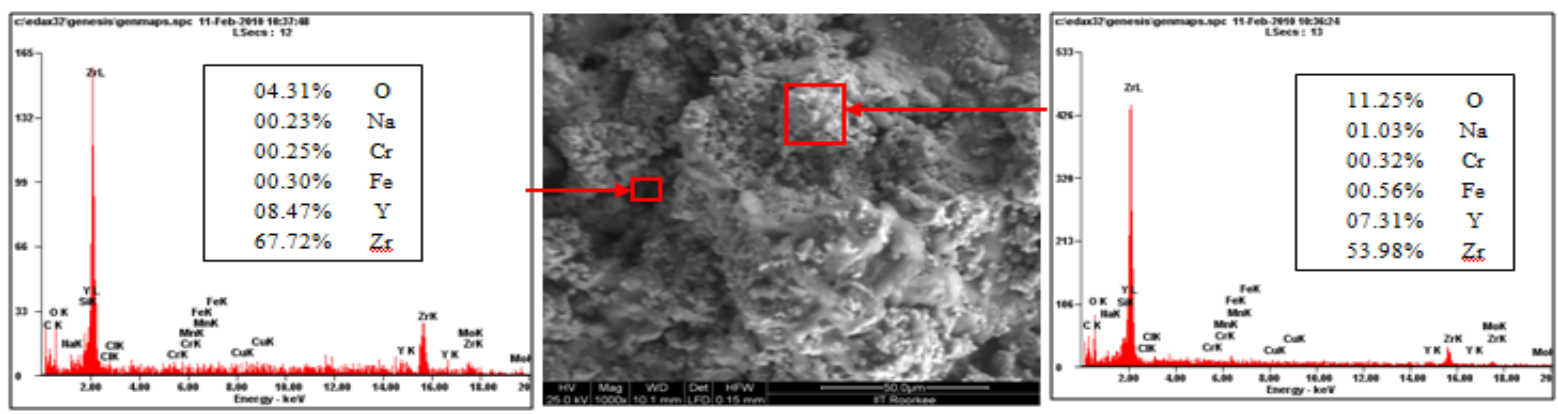

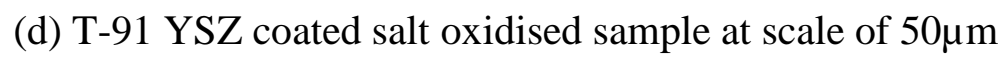

Fig. 6.Surface scale morphology and EDAX analysis (wt. \%) for T-91 bare and YSZ coated sample subjected to the cyclic oxidation at $900^{\circ} \mathrm{C}$ for 50 cycles in air and $75 \mathrm{wt}$ \% $\mathrm{Na}_{2} \mathrm{SO}_{4}+25$ wt. \% $\mathrm{NaCl}$ salt environment.

EDAX analysis of T-91 YSZ coated air oxidised sample Fig. 6(c) reveals the formation of $\mathrm{ZrO}_{2}$ and $\mathrm{Y}_{2} \mathrm{O}_{3}$ which prevented the oxidising media to interact directly with substrate but in this cracking of coating occured hence corrosion occured beneath the coating. In case of T-91 YSZ coated salt oxidised sample Fig. 6(d) along with formation of $\mathrm{ZrO}_{2}$ and $\mathrm{Y}_{2} \mathrm{O}_{3}$, there is an extra phase of $\mathrm{ZrS}$ as analysed from XRD pattern.

\subsubsection{Cross-sectional scale}

The cross sectional analysis of T-91 bare air oxidised sample Fig. 7 (a) shows a thin oxide layer formed on surface which shows that till point 5 all elements are constant in weight percent and after that ferrous starts to deplete and oxygen rises slightly. At point 8 all the elemental wt. \% goes down. In T-91 bare salt oxidised sample Fig. 7 (b) three distinct layers 
can be seen and first two layers have same composition without any variation in wt. \% of elements which shows that second layer is also parent material but it has parted of from substrate. Cross sectional analysis of T-91 YSZ coated air oxidised sample Fig. 7 (c) shows that corrosion occurred between the substrate and coating layer i.e. between point 2 and 7 . It can be seen that at point 2 there is start of corrosion which is separated clearly from substrate and from point 3 to 6 wt. \% of ferrous and oxygen is high as compared to other. From point 7 to 8 bond coat layer is present which is revealed by presence of nickel and at point 9 small proportion of yttrium and zirconium layer along with ferrous and oxygen is present. This case of intermediate corrosion occurred due to cracking of coating and penetration of corroding media through it. In case of T-91 YSZ coated salt oxidised sample Fig. 7 (d) there was no corrosion at substrate as the wt. \% of ferrous went on depleting. From point 2-4 it shows the presence of bond coat and from point 5-7 it shows the high wt. \% of zirconium and yttrium which shows the presence of YSZ top coat.

Elemental x-ray mapping analysis of T-91 bare air oxidised sample is shown in Fig.8. The micrograph indicates a thin oxide scale which mainly contains chromium and oxygen with some amount of manganese.

In case of T-91 bare salt oxidised sample more protection is achieved than T-91 bare air oxidised sample. From Fig.9 three layers are observed and in this first two layers are of substrate, the only thing is that second layer is cracked and parted off from parent substrate material where little accumulation of oxygen is revealed and chromium is fairly distributed all over, but as compared to ferrous, chromium has very dense layer in oxide scale along with oxygen as revealed from Fig.9. In the initial region of third layer a dense layer of molybdenum is also present. Hence here also we can say that $\mathrm{Cr}$ and $\mathrm{O}$ is playing major role for achieved protection.

According to cross-sectional study of T-91 YSZ coated air oxidised sample and macroscopic view Fig. 3(c) and Fig.10 it is observed that protective coating is cracked and the oxidising media has entered through these discontinuities and corrosion has occurred beneath the coating. According to elemental mapping it is observed that $\mathrm{Al}$ is diffused towards substrate material from bond coat. 

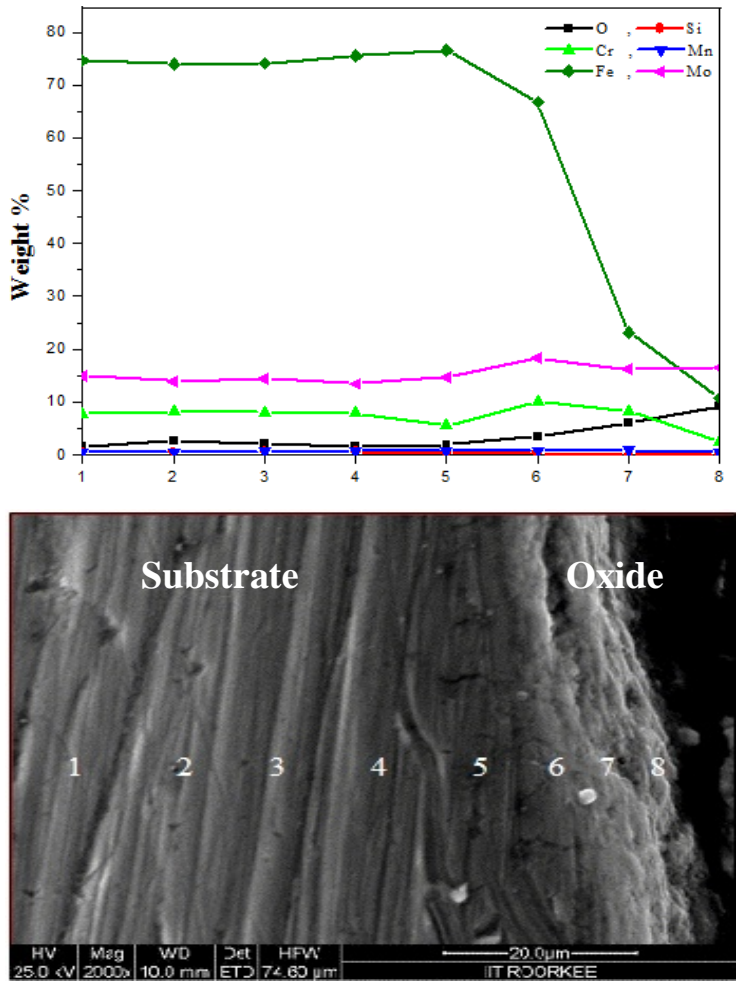

(a) T-91 bare air oxidised sample
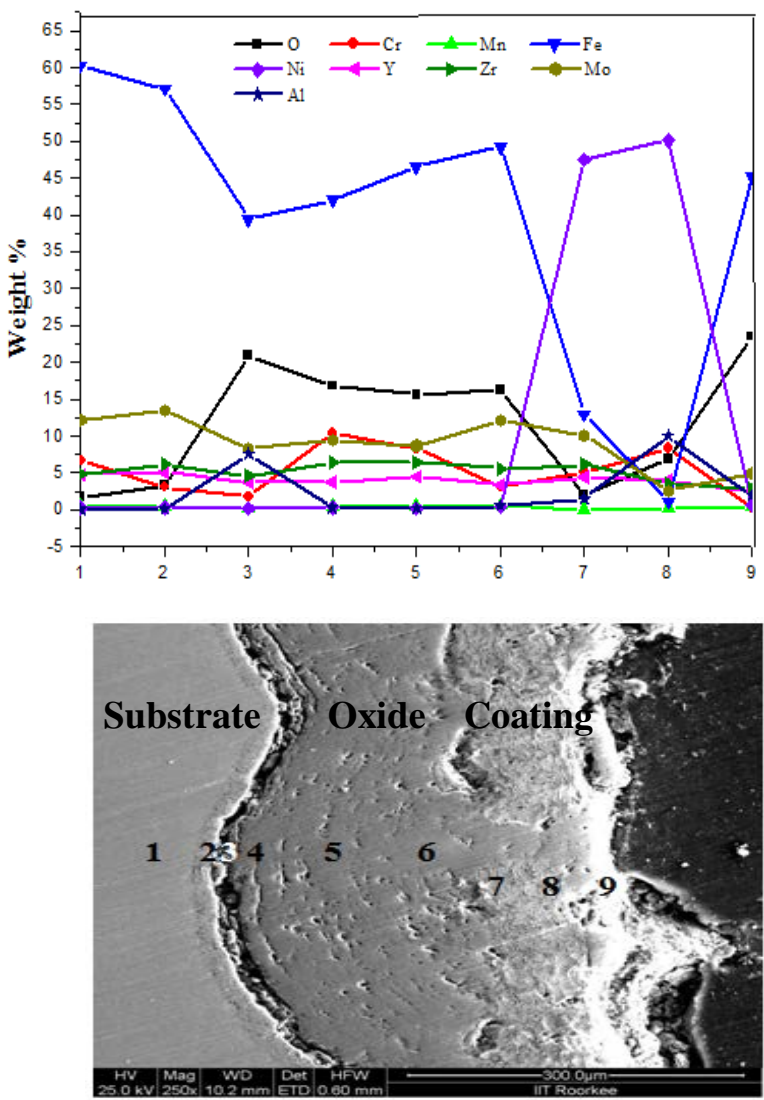

(c) T-91 YSZ coated air oxidised sample
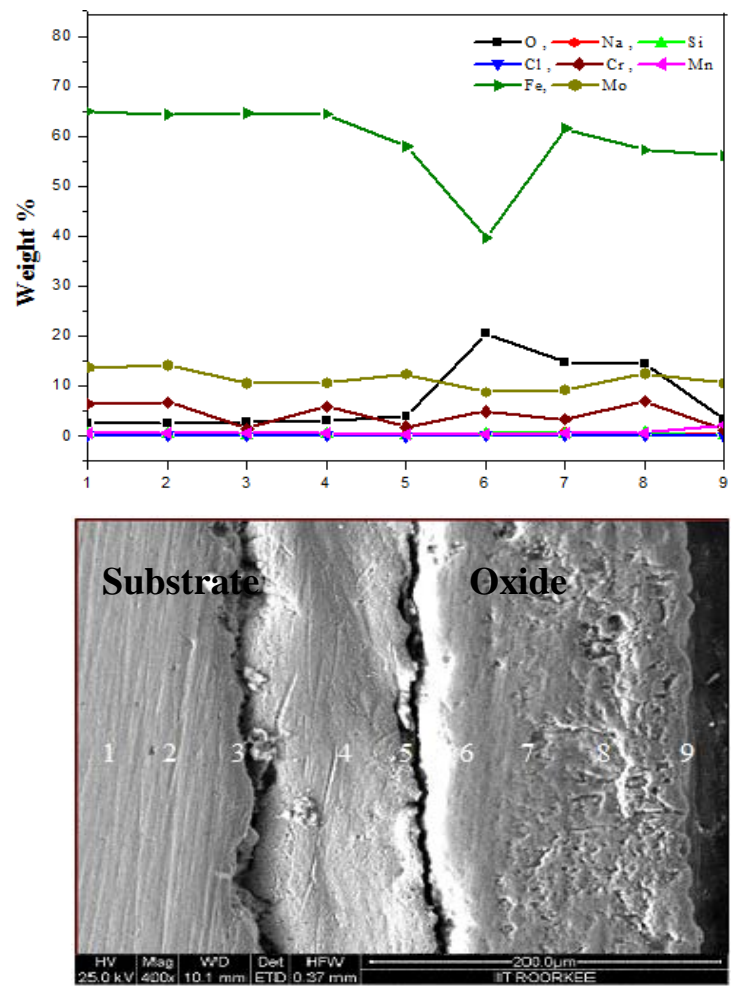

(b) T-91 bare salt oxidised sample
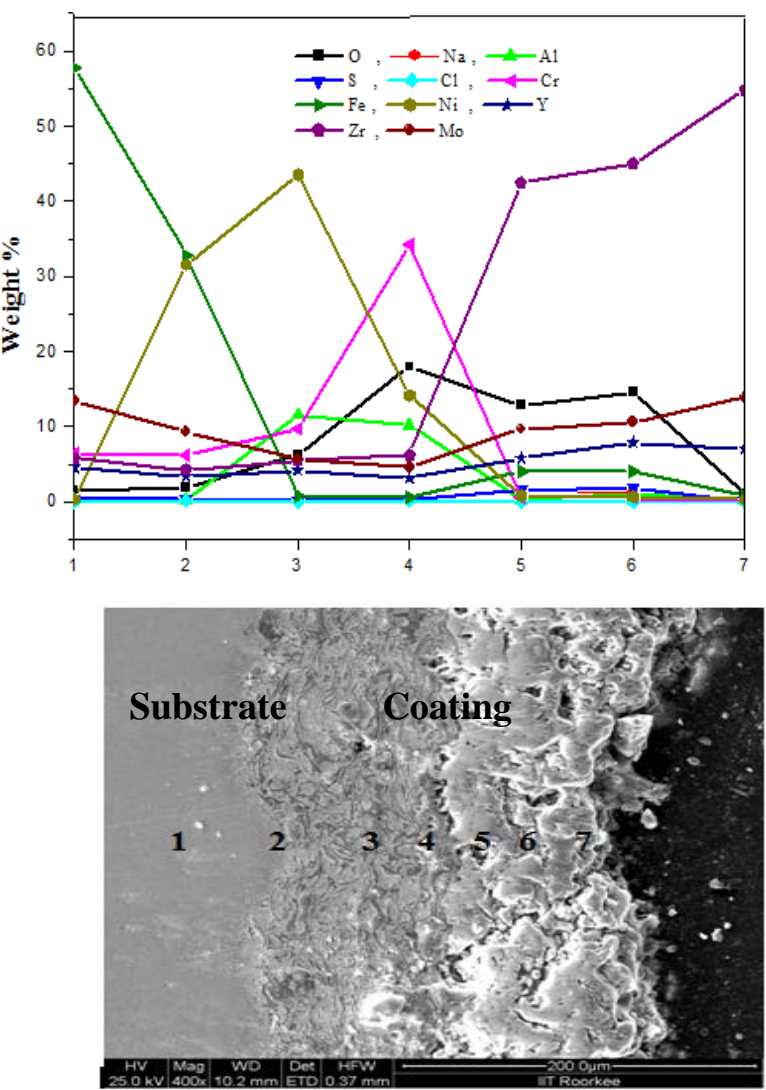

(d) T-91 YSZ coated salt oxidised sample

Fig.7. Oxide scale morphology and elemental composition variation across the cross section of T-91 bare and YSZ coated sample exposed to air and salt environment at $900^{\circ} \mathrm{C}$ for 50 cycles. 
In this layer wise corrosion occurred and the comprising layers are of $\mathrm{Fe}, \mathrm{Cr}$ and O. From Fig 10 it is also revealed that due to cracking of coating layer the corrosion product is also formed at surface of sample. Fe is diffused at surface from the crack and presence of $O$ is also revealed in that region and along with this aluminium from bond coat is also diffused towards the surface.

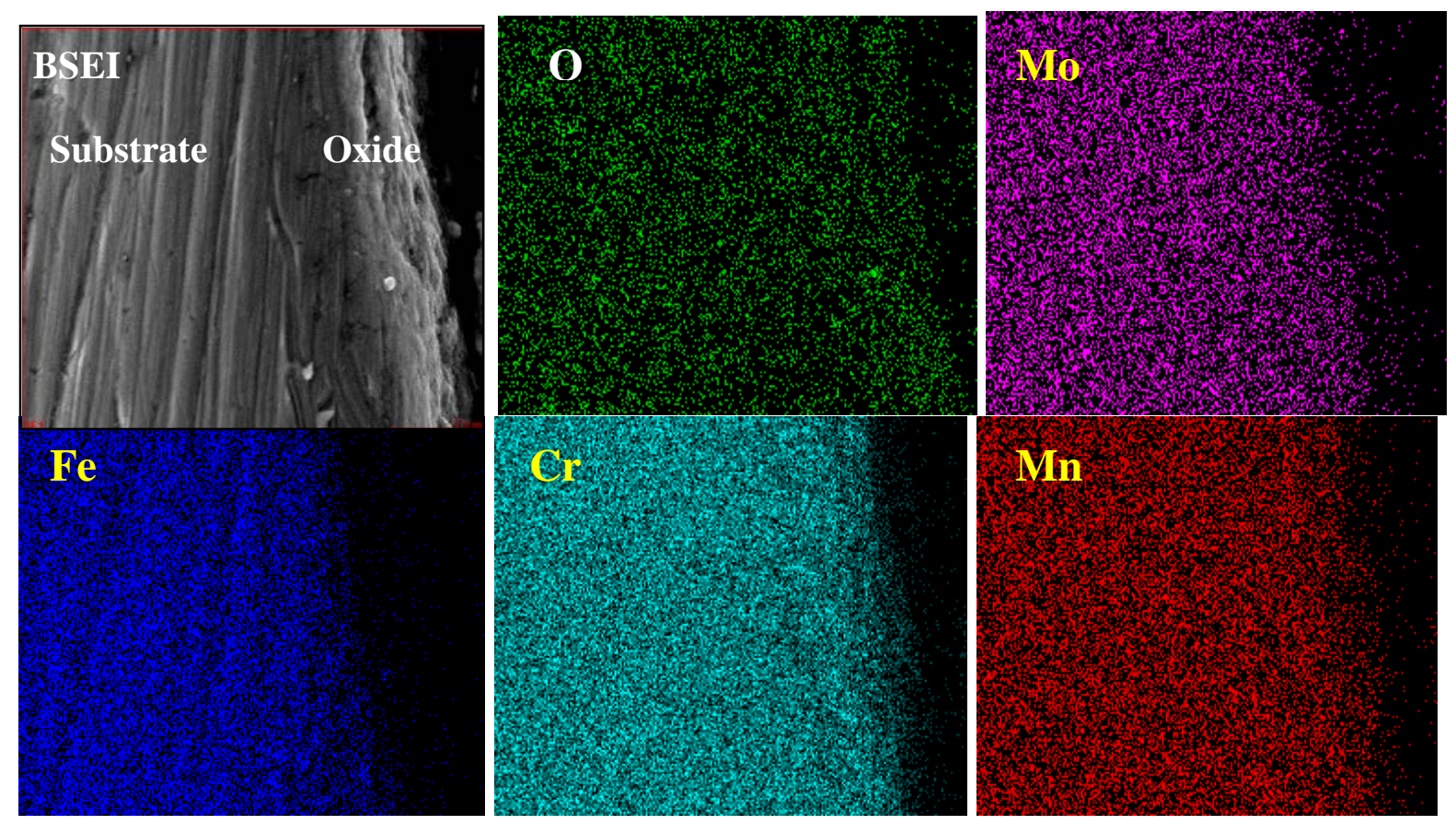

Fig. 8. BSEI and elemental X-ray mapping of the cross-section of T-91 bare sample exposed to cyclic hot corrosion in air at $900^{\circ} \mathrm{C}$ for 50 cycles.

According to cross-sectional study of T-91 YSZ coated salt oxidised sample Fig.10 it is observed that very high rate of corrosion protection is achieved and bond coat as well as top coat both are in well intact of substrate material. From Fig. 10 it is also observed that some $\mathrm{Fe}$ and $\mathrm{Al}$ are diffused towards surface and reveals the presence in pockets of top coat. In this mainly yttrium is dispersed all over the area uniformly and a dense layer of zirconium is present in the region of YSZ top coat.

\section{DISCUSSION}

Internal oxidation further led to the cracking of the scale due to the different thermal expansion coefficients of oxides in the scale from that of coating as suggested by $\mathrm{P}$. Niranatlumpong [14]. This has further been supported by the findings of R.A. Rapp and P.S.Liu [15-16], where it has been observed that development of stresses due to difference in 
thermal expansion coefficients. Through these cracks and irregularities, corrosive gases can penetrate to the base material and will thus allow significant grain boundary corrosion attack [17-19]. Inspite of cracking, in some cases like T-91 air oxidised sample, little weight gain has been recorded. Zirconia-based TBCs require alloying oxides such as $\mathrm{Y}_{2} \mathrm{O}_{3}, \mathrm{CaO}, \mathrm{CeO}$, MgO, etc., in order to stabilize a single-phase material, usually in the tetragonal form [28]. At room temperature the equilibrium phases of yttria partially stabilized zirconia are expected to be a low yttria content monoclinic phase and a high yttria content cubic phase. However, due to rapid cooling .During the plasma-spraying process, a non-equilibrium tetragonal phase takes place [20-22].
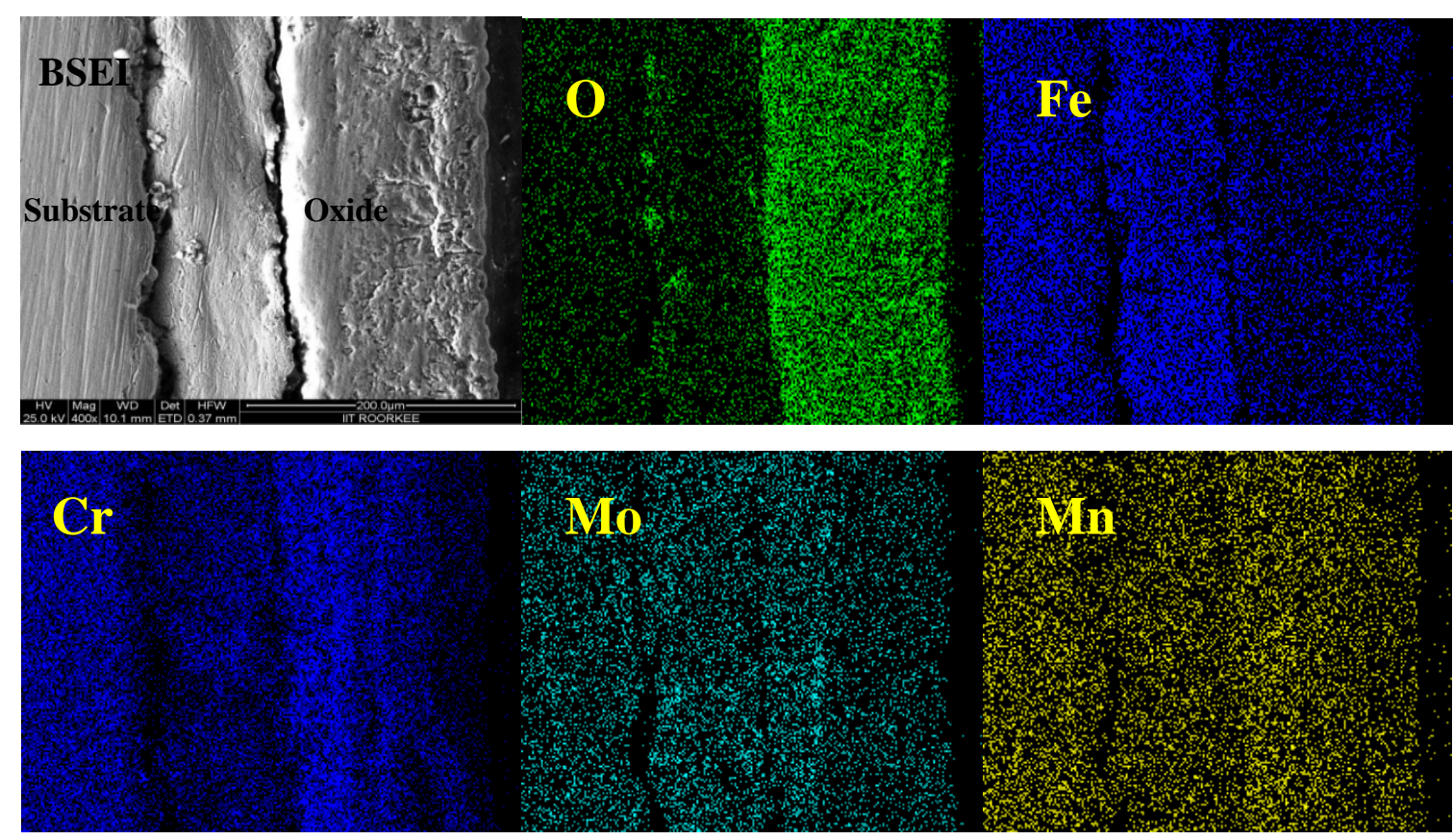

Fig.9. BSEI and elemental X-ray mapping of the cross-section of T-91 bare sample exposed to cyclic hot corrosion at $900^{\circ} \mathrm{C}$ for 50 cycles in 75 wt. $\% \mathrm{Na}_{2} \mathrm{SO}_{4}+25$ wt. \% NaCl salt.

A possible hot corrosion mechanism in zirconia-based TBCs can be divided into three steps. The first step is salt \& other corroding media penetration into the entire thickness of the zirconia top coating layer through splat boundaries and other coating defects such as microcracks and open pores. This step is accomplished very fast. The second step is the reaction of penetrated salts \& other corroding media with tetragonal stabilizers in zirconia. Because each zirconia splat is surrounded by the corroding media in the entire area of the zirconia coating layer, the depletion of stabilizers in zirconia and consequent phase transformation to monoclinic can occur in a very rapid and effective manner. Because of the 
volume expansion effect, accompanied with monoclinic phase transformation, results in unexpected failure under thermal shock conditions with a corrosive environment, this step is crucial and should be carefully considered, especially in the case of YSZ TBC systems. The final step is macroscale damage by diffusion controlled salt attacks. The failure of YSZ is due to transformation of zirconia to fully monoclinic, which can be retarded or prevented by using more acidic stabilizers [23]. The result which were seen till now shows that YSZ coating is very much effective in providing protection from high temperature corrosion in case of both air and $75 \mathrm{wt}$. \% $\mathrm{Na}_{2} \mathrm{SO}_{4}+25 \mathrm{wt}$. \% $\mathrm{NaCl}$ salt environment. In case of YSZ coated salt oxidised sample there occurred no cracking till the end of 50 cycles which occurred in YSZ coated air oxidised sample.
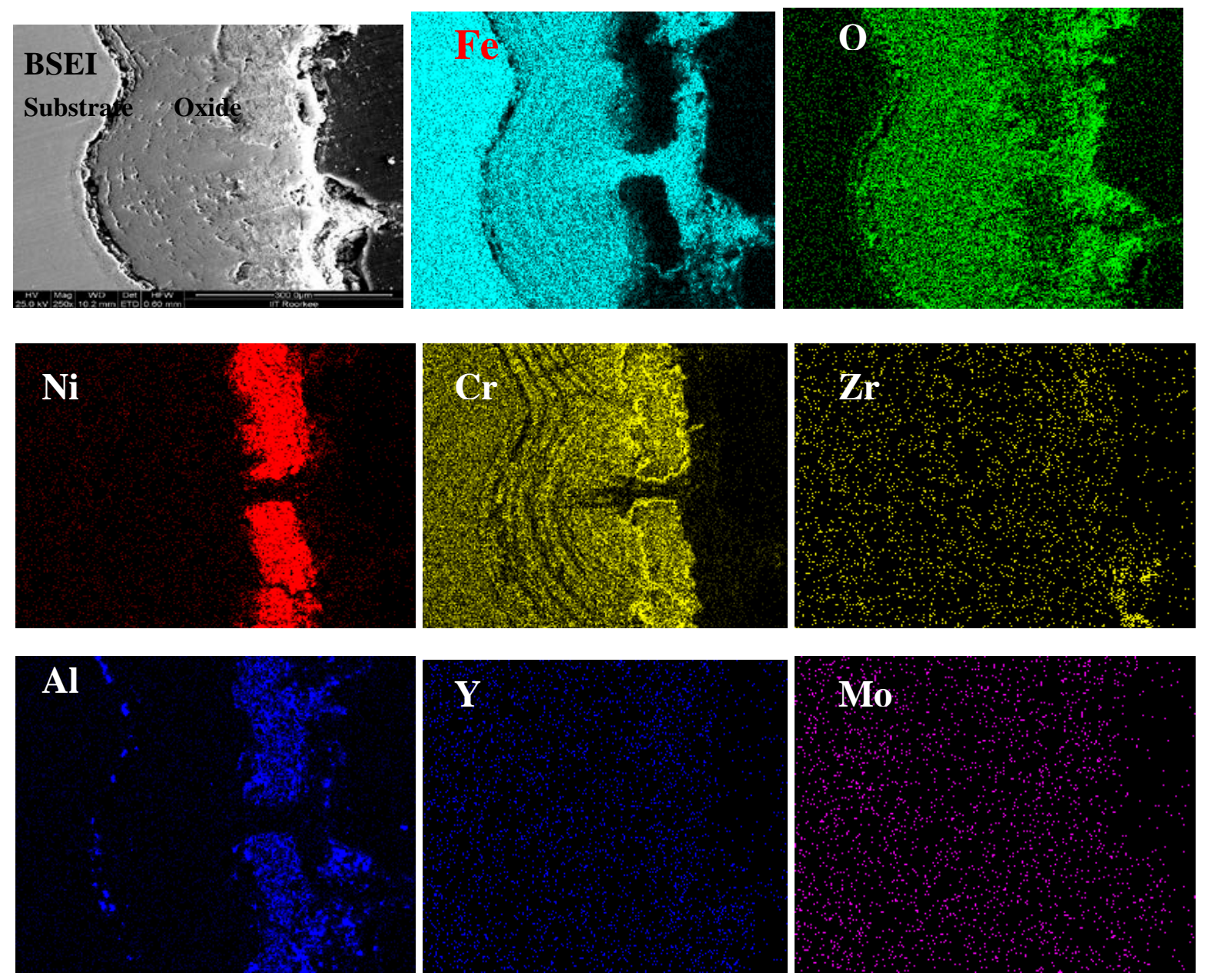

Fig.10. BSEI and elemental X-ray mapping of the cross-section of T-91 YSZ coated air oxidised sample exposed to cyclic hot corrosion at $900^{\circ} \mathrm{C}$ for 50 cycles.

\section{CONCLUSION}


The measured porosity value of plasma sprayed coating was $0.58 \%$ and this YSZ coated layer has provided very high resistance to corrosion and thereby increasing their workable life as compared to bare sample subjected to corrosion in both condition i.e. air and $75 \mathrm{wt}$. \% $\mathrm{Na}_{2} \mathrm{SO}_{4}+25 \mathrm{wt}$. \% NaCl salt environment. The cyclic oxidation of T-91 bare steel in air follow linear rate of weight gain and it has formed mainly hematite $\left(\mathrm{Fe}_{2} \mathrm{O}_{3}\right)$ at top surface. In case of T-91 bare steel in salt oxidised sample weight gain follows parabolic law and it has formed chromium iron oxide $(\mathrm{Cr}, \mathrm{Fe})_{2} \mathrm{O}_{3}$, chromium oxide $\mathrm{Cr}_{2} \mathrm{O}_{3}$ and hematite $\left(\mathrm{Fe}_{2} \mathrm{O}_{3}\right)$ at top surface. Cyclic oxidation of T-91 YSZ coated air oxidised sample resulted in cracking of coating due to volume expansion effect which resulted in unexpected failure under thermal shock conditions with corrosive environment but then to also the corrosion rate was too less as compared to bare sample as shown in Fig.1 and in case of T-91 YSZ coated salt oxidised sample cracking did not occurred and an extra phase of ZrS was revealed from XRD analysis.
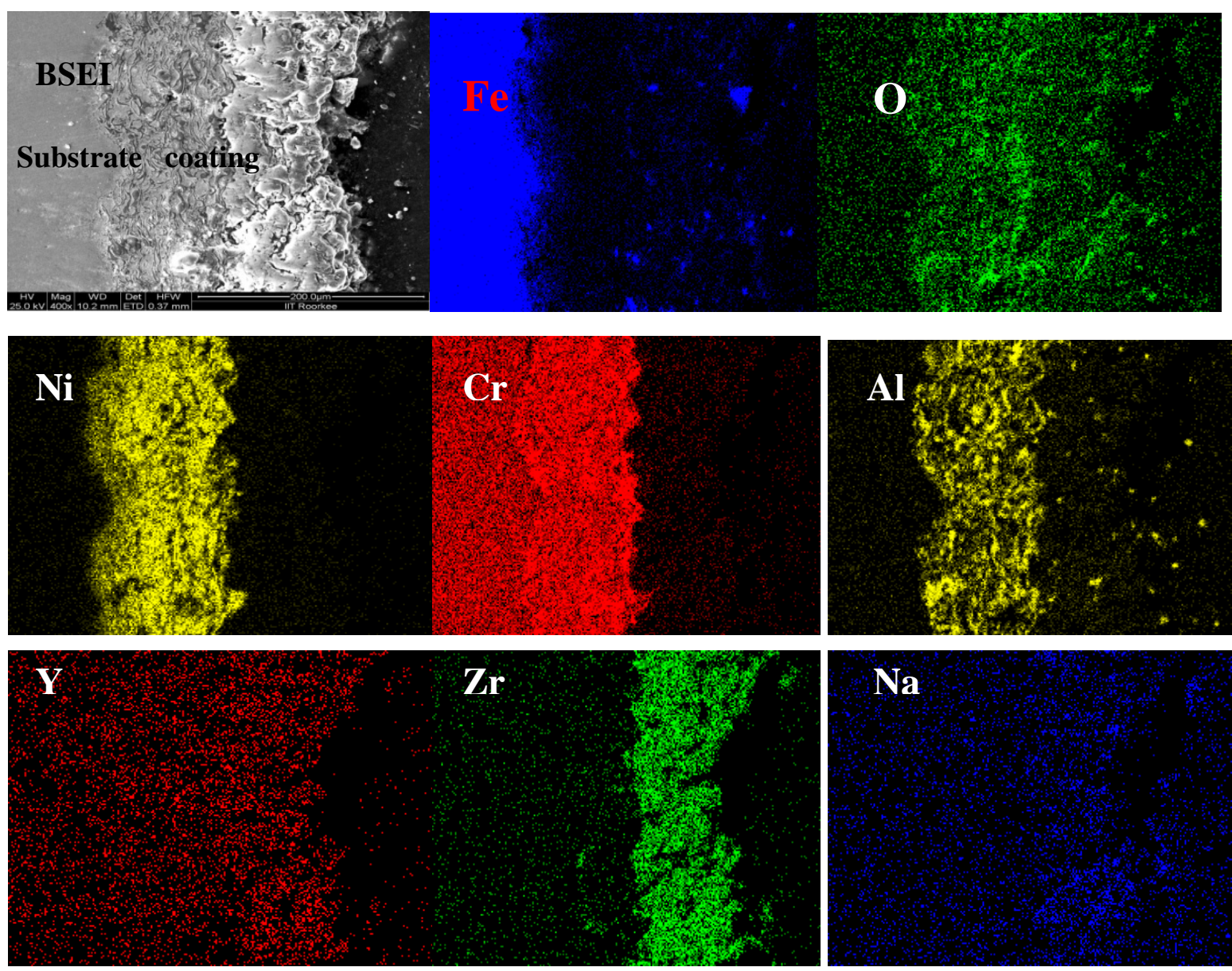

Fig.11. BSEI and elemental X-ray mapping of the cross-section of T-91 YSZ coated sample exposed to cyclic hot corrosion at $900^{\circ} \mathrm{C}$ for 50 cycles in salt of $75 \mathrm{wt}$. $\% \mathrm{Na}_{2} \mathrm{SO}_{4}+25 \mathrm{wt}$. \% $\mathrm{NaCl}$. 
The oxidation rate of T-91 YSZ coated air oxidised sample was too less i.e. nearly 53.79\% less as compared to bare steel and in case of T-91 YSZ coated salt oxidised sample more resistance to oxidation than the bare sample was achieved i.e. nearly $73.58 \%$ less at $900^{\circ} \mathrm{C}$ for 50 cycles.

\section{REFERENCES}

[1] K.G. Bundinski, Surface Engineering for Wear Resistance, Prentice-Hall, New Jersey, 1988.

[2] M.K. Hobbs, H. Reiter, Residual stresses in $\mathrm{ZrO}_{2}-8 \% \mathrm{Y}_{2} \mathrm{O}_{3}$ plasma sprayed thermal barrier coatings, in: D.L. Houck (Ed.), Thermal Spray: Advances in Coatings Technology, ASM International, 1989, 285-290.

[3] H. Herman, C.C. Berndt, H. Wang, Plasma sprayed ceramic coatings, in: J.B. Wachtman, R.A. Haber (Eds.), Ceramic Films and Coatings, Noyes Publications, New Jersey, 1993.

[4] L. Pawlowski, The Science and Engineering of Thermal Spray Coatings, Wiley, New York, 1995.

[5] A.G. Evans, D.R. Mumm, J.W. Hutchinson, G.H. Meier, F.S. Pettit, Prog. Mater. Sci. 46 (2001) 505.

[6] J.R. Brandon, R. Taylor, Surf. Coat. Techol. 69 (10) (1992) 75.

[7] I. Gurrappa, J. Mater. Sci. Lett. 17 (1998) 1267.

[8] R.L. Jones, J. Therm. Spray Technol. 6 (1) (1997 (March)) 77.

[9] B.A. Nagaraj, D.J. Wortman, Trans. ASME 112 (1990) 536.

[10] R. Srinivasan, J.M. Merrilea, Surf. Coat. Technol. 160 (2002) 187.

[11] R.L. Jones, J. Am. Ceram. Soc. 75 (7) (1992) 1818.

[12] K. Yamada, Y. Tomono, J. Morimoto, Y. Sasaki, A. Ohmori, Vacuum 65 (2002) 533540.

[13] R.A. Rapp, Y.S. Zhang, JOM, (1994 Dec) 47- 55.

[14] P. Niranatlumpong, C.B. Ponton, H.E. Evans, Oxid. Met. 53 (3-4) (2000) 241.

[15] R.A. Rapp, J.H. Devan, D.L. Douglass, P.C. Nordine, F.S. Pettit, D.P.Whittle, Mater. Sci.Eng.50 (1981) 1.

[16] P.S. Liu, K.M. Liang, H.Y. Zhou, S.R. Gu, X.F. Sun, H.R. Guan, T. Jin, K.N. Yang, Surf. Coat. Technol. 145 (2001) 75. 
[17] S. Danyluk, J.Y. Park, Corrosion 35 (12) (1979) 575.

[18] D. Wang, Surf. Coat. Technol. 36 (1988) 49.

[19] S.E. Sadique, A.H. Mollah, M.S. Islam, M.M. Ali, M.H.H. Megat, S.Basri, Oxid. Met. $54(5-6)(2000) 385$.

[20] R.A.Miller, R.G. Garlick, J.L. Smialek, Ceram. Bull. 62 (12) (1983) 1355.

[21] A.N. Khan, J. Lu, H. Liao, Mater. Sci. Eng., A Struct. Mater.: Prop.Microstruct. Process. 359 (2003) 129.

[22] C. Batista, A. Portinha, R.M. Ribeiro, V. Teixeira, C.R. Oliveira, Surf. Coat. Technol. 200 (2006) 6783-6791.

[23] S.Y. Park, J.H. Kim, M.C. Kim, H.S. Song, C.G. Park, Surf. Coat. Technol.190 (2005) 357-365. 